\title{
Testing Co-Volatility Spillovers for Natural Gas Spot, Futures and ETF Spot using Dynamic Conditional Covariances
}

Complutense de Análisis Económico

\author{
Chia-Lin Chang \\ Department of Applied Economics \\ Department of Finance National Chung Hsing University Taiwan
}

\section{Michael McAleer}

Department of Quantitative Finance National Tsing Hua University, Taiwan and Econometric Institute Erasmus School of Economics Erasmus University Rotterdam and

Tinbergen Institute, The Netherlands and

Department of Quantitative Economics Complutense University of Madrid, Spain

\section{Yanghuiting Wang}

Department of Quantitative Finance National Tsing Hua University

Taiwan

\section{Abstract}

There is substantial empirical evidence that energy and financial markets are closely connected. As one of the most widely-used energy resources worldwide, natural gas has a large daily trading volume. In order to hedge the risk of natural gas spot markets, a large number of hedging strategies can be used, especially with the rapid development of natural gas derivatives markets. These hedging instruments include natural gas futures and options, as well as Exchange Traded Fund (ETF) prices that are related to natural gas stock prices. The volatility spillover effect is the delayed effect of a returns shock in one physical, biological or financial asset on the subsequent volatility or co-volatility of another physical, biological or financial asset. Investigating volatility spillovers within and across energy and financial markets is a crucial aspect of constructing optimal dynamic hedging strategies. The paper tests and calculates spillover effects among natural gas spot, futures and ETF markets using the multivariate conditional volatility diagonal BEKK model. The data used include natural gas spot and futures returns data from two major international natural gas derivatives markets, namely NYMEX (USA) and ICE (UK), as well as ETF data of natural gas companies from the stock markets in the USA and UK. The empirical results show that there are significant spillover effects in natural gas spot, futures and ETF markets for both USA and UK. Such a result suggests that both natural gas futures and ETF products within and beyond the country might be considered when constructing optimal dynamic hedging strategies for natural gas spot prices.
\end{abstract}

Keywords Energy, natural gas, spot, futures, ETF, NYMEX, ICE, optimal hedging strategy, covolatility spillovers, diagonal BEKK.

JL Classification C58, D53, G13, G31, 013.

\section{Working Paper no 1610 \\ June, 2016}

COMPLUTENSE

MADRID

WEB DE LA COLECCIÓN: http://www.ucm.es/fundamentos-analisis-economico2/documentos-de-trabajo-del-icaeWorking papers are in draft form and are distributed for discussion. It may not be reproduced without permission of the author/s. 


\title{
Testing Co-Volatility Spillovers for
}

\section{Natural Gas Spot, Futures and ETF Spot using Dynamic Conditional Covariances*}

\author{
Chia-Lin Chang \\ Department of Applied Economics \\ Department of Finance \\ National Chung Hsing University \\ Taiwan \\ Michael McAleer \\ Department of Quantitative Finance \\ National Tsing Hua University \\ Taiwan \\ and \\ Econometric Institute \\ Erasmus School of Economics \\ Erasmus University Rotterdam \\ and \\ Department of Quantitative Economics \\ Complutense University of Madrid

\section{Yanghuiting Wang} \\ Department of Quantitative Finance \\ National Tsing Hua University \\ Taiwan
}

Revised: June, 2016

* The authors are grateful to Leh-Chyan So for helpful comments and suggestions. For financial support, the first author wishes to thank the National Science Council, Taiwan, and the second author acknowledges the Australian Research Council and the National Science Council, Taiwan. 


\begin{abstract}
There is substantial empirical evidence that energy and financial markets are closely connected. As one of the most widely-used energy resources worldwide, natural gas has a large daily trading volume. In order to hedge the risk of natural gas spot markets, a large number of hedging strategies can be used, especially with the rapid development of natural gas derivatives markets. These hedging instruments include natural gas futures and options, as well as Exchange Traded Fund (ETF) prices that are related to natural gas stock prices. The volatility spillover effect is the delayed effect of a returns shock in one physical, biological or financial asset on the subsequent volatility or co-volatility of another physical, biological or financial asset. Investigating volatility spillovers within and across energy and financial markets is a crucial aspect of constructing optimal dynamic hedging strategies. The paper tests and calculates spillover effects among natural gas spot, futures and ETF markets using the multivariate conditional volatility diagonal BEKK model. The data used include natural gas spot and futures returns data from two major international natural gas derivatives markets, namely NYMEX (USA) and ICE (UK), as well as ETF data of natural gas companies from the stock markets in the USA and UK. The empirical results show that there are significant spillover effects in natural gas spot, futures and ETF markets for both USA and UK. Such a result suggests that both natural gas futures and ETF products within and beyond the country might be considered when constructing optimal dynamic hedging strategies for natural gas spot prices.
\end{abstract}

Keywords: Energy, natural gas, spot, futures, ETF, NYMEX, ICE, optimal hedging strategy, covolatility spillovers, diagonal BEKK.

JEL: C58, D53, G13, G31, O13. 


\section{Introduction}

Natural gas is a vital component of the world's energy markets. It is cleaner than other fossil fuels and occupies an important position in the world's energy pantheon. Compared with other fossil fuels, natural gas is cleaner burning. It is an extremely important source of energy for reducing pollution, contributing to health, and maintaining a clean natural environment. Natural gas will release a lower ratio of carbon emissions than coal and oil in the production of the same units of heat.

According to data from the US Energy Information Administration (EIA), Carbon Dioxide Emissions of natural gas is $53.1 \mathrm{~kg} / \mathrm{million} \mathrm{Btu}^{\mathrm{a}}$, while coal has 95.3 $\mathrm{kg} /$ million Btu, gasoline has $71.3 \mathrm{~kg} /$ million Btu, and Kerosene has $72.3 \mathrm{~kg} / \mathrm{million}$ Btu. As carbon dioxide is a well-known greenhouse gas, the use of natural gas will have significant benefits for the environment.

Composed primarily of methane, the main products of the combustion of natural gas are carbon dioxide and water, while coal and oil are composed of much more complex molecules, such as nitrogen and sulfur. This means that, when combusted, natural gas releases very small amounts of harmful emissions, including nitrogen oxides (NOx) and sulfur dioxide (SO2), which degrade the environment and have a negative impact on health. The combustion of natural gas releases approximately no ash, substances that do not burn, but enter the atmosphere and contribute to the formation of smog.

Benefits from advances in natural gas exploration technology have led to large production and low prices. The production of natural gas has increased rapidly in the $21^{\text {st }}$ Century, especially in the USA. Such increases in natural gas production have come from shale gas resources, an unconventional gas, which is much more accessible and economical than conventional gas. Shale gas is natural gas trapped within shale formations, was developed in the USA just after 2000, and has become an increasingly important source of natural gas. In 2000 shale gas provided only 1\%

\footnotetext{
a British thermal unit: a Btu is the amount of heat required to raise the temperature of 1 avoirdupois pound of liquid water by 1 degree Fahrenheit at a constant pressure of one atmosphere.
} 
of USA natural gas production, but by 2015 it was approximately 56\%, according to data from the US EIA. The world's storage capacity of shale gas is quite large, especially in the USA, Canada, Argentina, Algeria and China. The USA and Canada already have significant shale gas production, while China has ambitious plans to increase shale gas production dramatically.

The prospect of ample natural gas supplies, continuing low prices, and the favorable environmental and economic position of natural gas, have led to expectations of continuing growth in the demand for natural gas, especially in the electricity and industrial sectors. Natural gas is now the third largest usable energy resource in the world, preceded only by oil products and coal. According to the 2015 Key World Energy Statistics published by the International Energy Agency (IEA), natural gas provided $21.4 \%$ of total energy supply, $21.7 \%$ of electricity generation, and $15.1 \%$ of total final consumption in the world in 2013.

The natural gas industry is an extremely important segment of the economy, including producers, processing plants, pipeline companies, storage operators, marketers and local distribution companies, with each group having a large number of companies.

Natural gas has many applications, primarily in electric power, industry, transportation and residential use, such as house heating and cooking. Electricity generation is the fastest growing use of natural gas. Data from the 2015 Key World Energy Statistics show that the share of natural gas in electricity generation has risen from $12.1 \%$ in 1973 to $21.7 \%$ in 2013 . In the industrial sector, natural gas also has a broad range of usefulness, both as a source of heat and power and as an input for producing plastics and chemicals.

As for the transportation sector, compressed natural gas has been used as transportation fuel, especially in public transit. Residual use is another major consumption of natural gas. Referring to data in 2013 from the US Department of Energy, about one-half of US homes used natural gas for heating, and 70\% of new homes were built using gas heating systems. 
Natural gas is also a critical energy source for energy markets in the future. According to data from the US Energy Administration (EIA), natural gas will occupy a greater proportion in the USA in both the energy consumption and electricity generation sectors for the next 30 years. The situation of primary energy consumption and electricity generation by fuel in the USA from 1980 to 2040 is shown in Figures 1 and 2. In 1990, the consumption of natural gas occupied only $23 \%$ of total energy consumption in USA, which had risen to $27 \%$ in 2013, and is predicted to rise to $29 \%$ in 2040. The proportion of natural gas in electricity generation also increased from $16 \%$ in 1990 to $27 \%$ in 2013, and is expected to reach $31 \%$ in 2040.

\section{[Insert Figures 1 and 2 here]}

Each country has their own strategy for natural gas, with most countries being willing to develop natural gas industries. The US Government believes that natural gas resources are a critical transitional energy during the process of transforming from fossil fuel to clean and renewable energy, and has displayed a willingness to provide policy support for natural gas development. The shale gas revolution led by the US Government has made natural gas prices fall rapidly, and has promoted the transformation of coal to gas for electricity generation. The UK Government has also changed their focus from wind and solar energy to natural gas and nuclear energy. Despite their reliance on diesel fuel for several decades, the German Government has begun to promote natural gas as a new type of motor vehicle fuel since the 1990s.

Since the Fukushima nuclear crisis, Japan's consumption of natural gas has risen rapidly, and the Japanese Government has placed great emphasis on natural gas strategies. China has also committed to developing the natural gas industry in order to reduce carbon emissions. France has been more willing to invest in green and renewable energy, such as wind energy, solar energy, wave energy, and bio-fuel. In general, natural gas will play an important role in the future of energy markets.

Unlike other internationally-traded commodity markets, natural gas has disparate regional benchmark prices. For instance, the Henry Hub price is the major benchmark of natural gas spot prices in USA. In the UK, the National Balancing Point (NBP) gas market is Europe's oldest spot-traded natural gas market, and publishes daily data of 
natural gas prices. There are many other regional benchmark prices, such as the Canadian Gas Price Reporter (CGPR) Daily, prices published by the Dutch Title Transfer Facility (TTF), German NetConnect Germany (NCG) and GASPOOL, Belgian Zeeburgge Tradint Point (ZTP), and French Powernext exchange (PEG), among others.

The derivatives markets for natural gas have grown rapidly from their inception. NYMEX published the first natural gas futures in 1990, with great success. Derivatives markets for natural gas have recently become the second largest source of energy derivatives, exceeded only by crude oil. According to the 2014 FIA Annual Volume Survey, Futures Industry Association (FIA), on the basis of trading volume, there are five futures or option contracts based on natural gas rankings in the top 20 energy futures and option contracts. Table 1 lists the Top 20 Energy Futures and Options Contracts in 2004.

\section{[Insert Table 1 here]}

There are two major natural gas derivatives exchanges, namely, the New York Mercantile Exchange (NYMEX) and the Intercontinental Exchange (ICE). NYMEX is owned and operated by the CME (Chicago Mercantile Exchange) Group. NYMEX published the first natural gas futures in 1990, and has already published 10 kinds of futures or options contracts for natural gas. The NYMEX natural gas futures contract prices have been used widely as a reference price for natural gas. Its contract trading unit for each hand is 10000 MMBtu (million British thermal units), and the delivery point is Louisiana Henry Hub.

ICE is the world's third-largest futures exchange, and owns and operates 23 regulated exchanges and marketplaces in different regions, including the USA, Canada and Europe. Up to 2015, ICE owned nearly 200 kinds of contracts related to natural gas or the natural gas index, and also provided the related Over the Counter (OTC) services and products, such as forward prices and swaps.

In addition to exchange-traded natural gas futures and option contracts, natural gas derivative contracts are also traded in OTC markets. The OTC market is a market 
where financial instruments such as currencies, stocks and commodities are traded directly between two parties, and the agreements are all made based on non-standardized mutual consent, which is different from financial instruments traded on stock exchanges. The bilateral trading that occurs in OTC markets includes forward contracts and swaps, which are generally non-standardized contracts that can be tailored to the specific needs of the counterparties involved in the transaction.

Apart from trading derivatives of natural gas, investing in natural gas ETF is also a convenient approach to gain exposure to natural gas spot prices. As an emerging component of energy ETF, natural gas ETF is quite popular among investors.

An ETF (exchange-traded fund) is a passively managed investment fund that may be traded on stock exchanges. Most ETFs track a stock index, such as S\&P 500 or Dow Jones Industrial Average. There are also other kinds of ETFs. For example, a currency ETF tracks a currency index or a foreign exchange, and commodity ETFs track the prices of commodities or commodity indices, including metals, energy and agricultural products. Due to the inherently low costs and tax efficiency, ETFs are very popular. Compared with futures contracts, investing in ETFs does not need to consider maturity dates or margins, which is an attractive prospect for investors.

Natural gas ETFs are varied. For example, UNG (United States Natural Gas Fund), one of the most popular natural gas ETFs, tracks Henry Hub natural gas spot prices by holding near-month natural gas futures contracts (including futures contracts traded in both NYMEX and ICE), and also forward and swap contracts. As distinct from UNG, DGAZ (VelocityShares 3X Inverse Natural Gas ETN) provides three times the negative exposure to the S\&P GSCI Natural Gas Excess Return Index for a one-day holding period. There are also natural gas ETFs that track stock prices of natural gas companies, such as FCG (First Trust ISE-Revere Natural Gas Index Fund). FCG tracks the 'ISE-REVERE Natural Gas Index', an equally weighted index of US companies that derives a substantial portion of their revenue from the exploration and production of natural gas.

As one of the most widely used energy resources worldwide, natural gas has a large daily trading volume, so that its spot markets are full of risks. Figure 3 shows the 
Henry Hub daily spot prices and UK NBP natural gas spot prices from February 3, 1997 to April 15, 2016. As the spot price of natural gas changes considerably in both the US and UK markets, it is self-evident that dynamic hedging strategies should be taken in natural gas markets.

\section{[Insert Figure 3 here]}

Volatility spillovers appear to be widespread in financial markets (Milunovich and Thorp, 2006), including energy futures markets (Lin and Tamvakis, 2001), and are important for constructing an appropriate dynamic hedging strategy. A volatility spillover occurs when changes in return shocks in one market produce a lagged impact on volatility in other markets, over and above local effects.

However, testing for spillovers in the literature is typically both confused and confusing. Spillover effects can be examined in the conditional means or in the conditional volatility of the shocks to returns (see Chang et al. (2015)). When volatility spillover effects are tested, univariate conditional volatility models, such as ARCH and GARCH, as well as multivariate conditional volatility models, including variations of BEKK, are among the most widely-used models..

McAleer et al. (2008) have shown that the Quasi Maximum Likelihood Estimates (QMLE) of the parameters in the BEKK model are consistent and asymptotically normal only when the covariance matrix of the random coefficient is diagonal or scalar. The full BEKK model has no underlying stochastic process, and hence no associated regularity conditions. Therefore, any purported asymptotic properties hold only by assumption (see Chang et al. (2015)), and none of the purported tests of volatility spillover effects using the full BEKK model has any statistical validity. However, most of the published papers in the literature testing for volatility spillovers have used the problematic full BEKK model, which certainly suggests that much of the empirical research is highly questionable.

Indeed, many so-called tests of spillovers in the literature are not actually tests of spillover. Therefore, the paper will estimate models using the three definitions of 
volatility spillovers of Chang et al. (2015), specifically full volatility, full co-volatility and partial co-volatility spillovers, and test the partial co-volatility spillover effects among the natural gas spot, futures and ETF markets by using the diagonal BEKK model.

In light of the above, the three primary purposes of the paper are as follows:

(1) analyze the natural gas industry, emphasizing the key issues that drive various aspects of natural gas across commodities, data sources, and financial derivatives;

(2) estimate multivariate conditional covariance models, namely diagonal BEKK, using the returns on spot, futures and ETF prices for the USA and UK;

(3) calculate co-volatility spillovers among natural gas spot, futures and ETF markets, both within and outside the US and UK energy markets.

The remainder of the paper is presented as follows. Section 2 reviews the brief extant literature on volatility spillovers. Section 3 introduces volatility models in detail. The data and empirical analysis is presented in Section 4. Section 5 gives some concluding comments.

\section{Literature on Volatility Spillovers}

Substantial research has been undertaken on testing volatility spillover effects within and across energy spot, futures, and ETF markets in the energy sector.

With the development of the ARCH model of Engle (1982) and GARCH model of Bollerslev (1986), the literature in the early 2000s focused on using these univariate conditional volatility models to test volatility spillovers using energy data. Lin et al. (2001) seems to have been the first attempt to examine spillover effects in energy markets. The authors investigate volatility spillover effects between crude oil contracts of NYMEX and IPE using both ARCH and GARCH models, and find the existence of 
substantial spillover effects. Hammoudeh et al. (2003) examine both mean and volatility spillovers among spot and futures prices for crude oil, heating oil and gasoline, using co-integration methods, error-correction representations, and GARCH models.

Subsequently, all estimation and testing of spillover effects seems to have shifted to multivariate GARCH models, including variations of the BEKK model of Baba et al. (1985) and Engle and Kroner (1995), and the DCC model of Engle (2002). Ewing et al. (2002) estimate a full BEKK model to test simultaneously how the volatility in the oil and natural gas sectors changes over time and across markets. The empirical results show that volatility spillovers exist between the oil and natural gas markets.

From a risk management perspective, Haigh et al. (2002) model the time-varying volatility spillovers among the crude oil, heating oil, and natural gas futures markets using multivariate GARCH models, and find the volatility spillovers between the markets are not only significant, but are also able to assist in reducing risks.

In order to investigate the determinants of price volatility in energy futures markets and forecast volatility in energy markets, Karali et al. (2014) analyze the spillover effects in crude oil, heating oil, and natural gas futures markets using the problematic full BEKK model. Bi-directional volatility spillover effects were found between natural gas and crude oil, and between the natural gas and heating oil markets.

As natural gas has recently occupied an increasingly important position in electricity generation, especially in the USA, Efimova et al. (2014) focused on investigating the volatilities of the oil, natural gas, and electricity markets in USA. Trivariate BEKK and DCC models were used to observe volatility spillovers among the energy and electricity markets. The empirical results show significant interactions among the three markets, including volatility spillovers from one asset to another. The performance of estimating and forecasting univariate and multivariate models were also be compared, with the estimates from the univariate and multivariate models being broadly similar, while the forecasts from the univariate models were determined to be more accurate. 
Despite the widely used full BEKK and DCC models, alternative multivariate volatility models are available, such as the constant conditional correlation (CCC) model of Bollerslev (1990), the varying conditional correlation (VCC) model of Tse and Tsui (2002), the vector ARMA-GARCH (VARMA-GARCH) model of Ling and McAleer (2003), and the VARMA-asymmetric GARCH (VARMA-AGARCH) model of McAleer et al. (2009). McAleer (2005) provides further details for most of these multivariate models. In practice, there are also substantial applications of each of these multivariate models.

For purposes of testing volatility spillovers between crude oil futures prices and oil company stocks prices, Chang et al. (2010) analysed the volatility spillovers and asymmetric effects across and within four major benchmarks of crude oil markets: WTI, Brent, Dubai/Oman and Tapis, by using multivariate GARCH models, namely CCC, VARMA-GARCH and VARMA-AGARCH. The results presented some volatility spillover effects between Brent and WTI returns, and from the Brent and WTI crude oil markets to the Dubai and Tapis markets. These empirical results confirm that the Brent and WTI crude oil markets are the international benchmarks for crude oil.

In order to hedge the risks of crude oil spot and futures prices, Chang et al. (2011) investigated the effectiveness of the BEKK, diagonal BEKK, CCC, DCC, and VARMA-GARCH models. Two major benchmark international crude oil markets, Brent and WTI crude oil prices, are considered in the empirical analysis. Volatility spillover effects between spot and futures returns are found in both the Brent and WTI markets.

As a clear and accurate definition of volatility spillovers have recently been provided by Chang et al. (2015), namely full volatility, full co-volatility and partial co-volatility spillovers, virtually all the previous testing of so-called "volatility spillovers" in the literature are highly questionable. Chang, McAleer and Wang (2016) seems to have been the first paper to estimate and calculate (partial) co-volatility spillovers that could be tested validly using the diagonal BEKK model.

In the paper, co-volatility spillover effects for spot and futures returns and bio-ethanol-related agricultural commodities, namely corn and sugar, are analysed 
using the diagonal BEKK model. The empirical results suggest significant positive co-volatility spillover effects among the futures markets of the three commodities, while negative co-volatility spillover effects occur only between the corn and sugar markets for spot prices.

Although spillover effects between the ETF and equity markets have been tested in several papers, including Chen et al. (2010), Chen (2011), Krause (2013) and Chang Hsieh, McAleer (2016), the literature on testing spillovers between the energy and ETF markets is sparse. The closest research is Sadorsky (2012), in which volatility spillovers between oil prices and stock prices of clean energy and technology companies, are analyzed using multivariate GARCH models.

The first paper that seems to have investigated energy ETF is Chang et al. (2014), in which the relationships between the flows and returns for five energy ETFs in the USA are examined using the VAR model. The empirical results show a negative relationship between energy returns and subsequent energy ETF flows, which has clear implications for spillover effects.

\section{Methodology}

As the primary purpose of the paper is to test for spillover effects for natural gas markets, the estimation of multivariate conditional volatility models, with appropriate regularity conditions and asymptotic properties of the Quasi Maximum Likelihood estimators (QMLE) of the parameters underlying the conditional means and conditional variances, is required.

This section is organized as follows:

(1) A brief introduction of the GARCH model, the most widely-used univariate conditional volatility model;

(2) A discussion of two popular multivariate conditional volatility models: diagonal BEKK and full BEKK models; 
(3) A definition of three novel types of volatility spillovers and the method of calculating covolatility spillover effects.

The analysis of univariate and multivariate conditional volatility models below follows closely the presentation in Chang et al. (2015)

The first step in estimating multivariate models is to obtain the standardized residuals from the conditional mean returns shocks. For this reason, the most widely-used univariate conditional volatility model, namely GARCH, will be presented briefly, followed by the two most widely estimated multivariate conditional covariance models, namely the diagonal and full BEKK models.

Consider the conditional mean of financial returns, as follows:

$y_{t}=E\left(y_{t} \mid I_{t-1}\right)+\varepsilon_{t}$

where the returns, $y_{t}=\Delta \log P_{t}$, represent the log-difference in financial commodity or agricultural prices, $P_{t}, I_{t-1}$ is the information set at time $t-1$, and $\varepsilon_{t}$ is conditionally heteroskedastic. In order to derive conditional volatility specifications, it is necessary to specify the stochastic processes underlying the returns shocks, $\varepsilon_{t}$.

\subsection{Univariate Conditional Volatility Models}

Alternative univariate conditional volatility models are of interest in single index models to describe individual financial assets and markets. Univariate conditional volatilities can also be used to standardize the conditional covariances in alternative multivariate conditional volatility models to estimate conditional correlations, which are particularly useful in developing optimal dynamic hedging strategies. The most popular univariate conditional volatility model, GARCH model, is discussed below.

Consider the random coefficient autoregressive process of order one underlying the return shocks, $\varepsilon_{t}$ : 
$\varepsilon_{t}=\phi_{t} \varepsilon_{t-1}+\eta_{t}$

where

$\phi_{t} \sim i i d(0, \alpha)$

$\eta_{t} \sim \operatorname{iid}(0, \omega)$,

and $\eta_{t}=\varepsilon_{t} / \sqrt{h_{t}}$ is the standardized residual.

Tsay (1987) derived the ARCH (1) model of Engle (1982) from equation (2) as:

$h_{t}=E\left(\varepsilon_{t}^{2} \mid I_{t-1}\right)=\omega+\alpha \varepsilon_{t-1}^{2}$

where $h_{t}$ represents conditional volatility, and $I_{t-1}$ is the information set available at time $t-1$.

The use of an infinite lag length for the random coefficient autoregressive process in equation (2), with appropriate geometric restrictions (or stability conditions) on the random coefficients, leads to the GARCH model of Bollerslev (1986). From the specification of equation (2), it is clear that both $\omega$ and $\alpha$ should be positive as they are the unconditional variances of two different stochastic processes.

The QMLE of the parameters of ARCH and GARCH have been shown to be consistent and asymptotically normal in several papers. For example, Ling and McAleer (2003) showed that the QMLE for GARCH $(p, q)$ is consistent if the second moment is finite. Moreover, a weak sufficient log-moment condition for the QMLE of GARCH $(1,1)$ to be consistent and asymptotically normal is given by:

$E\left(\log \left(\alpha \eta_{t}^{2}+\beta\right)\right)<0, \quad|\beta|<1$

which is not easy to check in practice as it involves two unknown parameters and a random variable. The more restrictive second moment condition, namely $\alpha+\beta<1$, is much easier to check in practice. 
In general, the proofs of the asymptotic properties follow from the fact that ARCH and GARCH can be derived from a random coefficient autoregressive process. McAleer et al. (2008) give a general proof of asymptotic normality for multivariate models that are based on proving that the regularity conditions satisfy the conditions given in Jeantheau (1998) for consistency, and the conditions given in Theorem 4.1.3 in Amemiya (1985) for asymptotic normality.

\subsection{Multivariate Conditional Volatility Models}

The multivariate extension of univariate GARCH is given in Baba et al. (1985) and Engle and Kroner (1995).

In order to establish volatility spillovers in a multivariate framework, it is useful to define the multivariate extension of the relationship between the returns shocks and the standardized residuals, that is, $\eta_{t}=\varepsilon_{t} / \sqrt{h_{t}}$. The multivariate extension of equation (1), namely $y_{t}=E\left(y_{t} \mid I_{t-1}\right)+\varepsilon_{t}$, can remain unchanged by assuming that the three components are now $m \times 1$ vectors, where $m$ is the number of financial assets. The multivariate definition of the relationship between $\varepsilon_{t}$ and $\eta_{t}$ is given as:

$\varepsilon_{t}=D_{t}^{1 / 2} \eta_{t}$

where $D_{t}=\operatorname{diag}\left(h_{1 t}, h_{7, t}, \ldots, h_{m t}\right)$ is a diagonal matrix comprising the univariate conditional volatilities.

Define the conditional covariance matrix of $\varepsilon_{t}$ as $Q_{t}$. As the $m \times 1$ vector, $\eta_{t}$, is assumed to be iid for all $m$ elements, the conditional correlation matrix of $\varepsilon_{t}$, which is equivalent to the conditional correlation matrix of $\eta_{t}$, is given by $\Gamma_{i}$. Therefore, the conditional expectation of (4) is defined as:

$Q_{+}=D_{t}^{1 / 2} \Gamma_{t} D_{+}^{1 / 2}$

Equivalently, the conditional correlation matrix, $\Gamma_{t}$, can be defined as: 
$\Gamma_{t}=D_{t}^{-1 / 2} Q_{t} D_{t}^{-1 / 2}$

Equation (5) is useful if a model of $\Gamma_{t}$ is available for purposes of estimating $Q_{p}$, whereas (6) is useful if a model of $Q_{t}$ is available for purposes of estimating $\Gamma_{t}$.

Equation (5) is convenient for a discussion of volatility spillover effects, while both equations (5) and (6) are instructive for a discussion of asymptotic properties. As the elements of $D_{t}$ are consistent and asymptotically normal, the consistency of $Q_{t}$ in (5) depends on consistent estimation of $\Gamma_{t}$, whereas the consistency of $\Gamma_{t}$ in (6) depends on consistent estimation of $Q_{t}$. As both $Q_{t}$ and $\Gamma_{t}$ are products of matrices, neither the QMLE of $Q_{t}$ nor $\Gamma_{t}$ will be asymptotically normal, based on the definitions given in equations (5) and (6).

\subsubsection{Diagonal and Scalar BEKK}

The diagonal BEKK model can be derived from a vector random coefficient autoregressive process of order one, which is the multivariate extension of the univariate process given in equation (1):

$\varepsilon_{t}=\Phi_{t} \varepsilon_{t-1}+\eta_{t}$

where

$\varepsilon_{t}$ and $\eta_{t}$ are $m \times 1$ vectors, $\Phi_{t}$ is an $m \times m$ matrix of random coefficients, and

$\Phi_{t} \sim \operatorname{iid}(0, A)$,

$\eta_{t} \sim \operatorname{iid}\left(0, C C^{\prime}\right.$

Technically, a vectorization of a full (that is, non-diagonal or non-scalar) matrix $A$ to vec $A$ can have dimension as high as $m^{2} \times m^{2}$, whereas vectorization of a symmetric matrix $A$ to vech $A$ can have dimension as low as $m(m-1) / 2 \times m(m-1) / 2$. 
In a case where $A$ is either a diagonal matrix or the special case of a scalar matrix, $A=a I_{m}$, McAleer et al. (2008) showed that the multivariate extension of GARCH(1,1) from equation (7), incorporating an infinite geometric lag in terms of the returns shocks, is given as the diagonal or scalar BEKK model, namely:

$Q_{t}=C C^{\prime}+A \varepsilon_{t-1} \varepsilon_{t-1}^{\prime} A^{\prime}+B Q_{t-1} B^{\prime}$

where $A$ and $B$ are both either diagonal or scalar matrices.

McAleer et al. (2008) showed that the QMLE of the parameters of the diagonal BEKK model were consistent and asymptotically normal, so that standard statistical inference on testing hypotheses is valid. Moreover, as $Q_{t}$ in (8) can be estimated consistently, $\Gamma_{f}$ in equation (6) can also be estimated consistently.

\subsubsection{Full BEKK model}

The full BEKK model, a multivariate extension of univariate GARCH, is given in Baba et al. (1985) and Engle and Kroner (1995), without actually deriving the model from an appropriate stochastic process:

$Q_{t}=C C^{\prime}+A \varepsilon_{t-1} \varepsilon_{t-1}^{\prime} A^{\prime}+B Q_{t-1} B^{\prime}$

except that $A$ and $B$ are both full, rather than diagonal or scalar matrices, as in (8).

The full BEKK model cannot be derived from any known underlying stochastic process, which means there are no valid asymptotic properties of the QMLE of the parameters. Moreover, as the number of parameters in a full BEKK model can be as much as $3 m(m+1) / 2$, the "curse of dimensionality" will be likely to arise, which means that convergence of the estimation algorithm can become problematic and less reliable when there is a large number of parameters to be estimated. As a matter of fact, estimation of the full BEKK can be problematic even when $m$ is as low as 5 financial assets. Such computational difficulties do not arise for the diagonal BEKK model. 


\subsection{Volatility spillover effects}

According to Chang, Li and McAleer (2015), spillovers can be defined in terms of full volatility spillovers and full co-volatility spillovers, as well as partial co-volatility spillovers, as follows:

1) Full volatility spillovers: $\partial Q_{i i t} / \partial \varepsilon_{k t-1}, k \neq i$

2) Full co-volatility spillovers: $\partial Q_{i j t} / \partial \varepsilon_{k t-1}, i \neq j, k \neq i, j$

3) Partial co-volatility spillovers: $\partial Q_{i j t} / \partial \varepsilon_{k t-1}, i \neq j, k=$ either $i$ or $j$

where $i, j, k=1 \ldots m ; \varepsilon_{t}$ denote the return shocks, and $Q_{t}$ is the conditional covariance matrix of $\varepsilon_{t}$.

The full BEKK model has full volatility spillovers, full co-volatility spillovers and partial co-volatility spillovers. As there are no asymptotic properties in the full BEKK model, any statistical analysis of the estimated parameters is not valid.

In terms of volatility spillovers of the diagonal BEKK model, as the off-diagonal elements in the second term on the right-hand side of equation (8), $A \varepsilon_{t-1} \varepsilon_{t-1}^{\prime} A^{\prime}$, have typical $(i, j)$ elements $a_{i i} a_{j j} \varepsilon_{i t-1} \varepsilon_{j t-1}, i \neq j, i, j=1, \ldots, m$, there are no full volatility or full covolatility spillovers. However, partial covolatility spillovers are not only possible, but they can also be tested using valid statistical procedures.

Diagonal BEKK provides the appropriate model to test partial co-volatility spillovers effect. The matrices $A$ and $B$ in equation (8) can be expressed as:

$A=\left[\begin{array}{ccc}a_{11} & \cdots & 0 \\ \vdots & \ddots & \vdots \\ 0 & \cdots & a_{m m}\end{array}\right], B=\left[\begin{array}{ccc}b_{11} & \cdots & 0 \\ \vdots & \ddots & \vdots \\ 0 & \cdots & b_{m m}\end{array}\right]$

where $a_{i i}>0$ and $\left|b_{j j}\right|<1, i, j=1, \ldots, m$. 
The partial co-volatility spillover effect from return shocks to commodity $i$ at $t-1$ to the co-volatility between commodities $i$ and $j$ at $t$, is defined as follows:

$\frac{\partial Q_{i j t}}{\partial \varepsilon_{i t-1}}=a_{i i} \times a_{j j} \times \varepsilon_{j t-1}, i \neq j$

Hence, the null hypothesis of the test for a co-volatility spillover effect is given as:

$H_{0}: a_{i i} a_{j j}=0$,

where the rejection of $H_{0}$ means there is a spillover effect from the return shock of $i$ at time $t-1\left(\varepsilon_{i t-1}\right)$ to the co-volatility between $i$ and $j$ at time $t\left(Q_{i j t}\right)$.

\section{Empirical Analysis}

\subsection{Data}

As there is no natural gas ETF to track UK natural gas prices or the stock prices of related companies, this means that the data for UK natural gas ETF prices are latent. A Natural Gas ETF price for the UK market can be contructed or generated by defining a "London ETF Spot" in a similar manner to that of the definition of FCG, the natural gas ETF for the USA.

FCG (First Trust ISE-Revere Natural Gas Index Fund) is a natural gas ETF traded in the NYSE Arca. This ETF tracks the ISE-Revere Natural Gas Index, which is an equally weighted index of US companies that derive a substantial portion of their activities from natural gas exploration and production. FCG provides investors with exposure to the global natural gas industry. The component companies of ISE-Revere Natural Gas Index are listed in Table 2.

We define the London ETF Spot is as follows: 
London ETF Spot tracks a stock index with equally weights on the share prices of UK natural gas exploration and production companies. The list of the six companies are in Table 3.

\section{[Insert Tables 2 and 3 here]}

An equally weighted index can be obtained by weighting equally the stock prices of the six companies.

According to the definition of London ETF Spot, its price is supposed to track the price of the equally weighted index, which will be referred to as Index, so we have:

Index $=$ London $E T F_{t}+v_{t}$

where London_ETF $F_{t}$ is the latent price of London ETF Spot at time $t$, Index $x_{t}$ is the observable price of the equally weighted index at time $t$, and the random error $v_{t} \sim i i d\left(0, \sigma_{n}^{2}\right)$.

According to Efficient Market Theory (see, for example, Fama (1970)), the price of the equally weighted index at time $t-1$ is able to explain its price at time $t$. As the London ETF Spot is based on UK markets, the UK NBP natural gas spot price and FTSE 100 index, which is a share index of the 100 companies listed on the London Stock Exchange with the highest market capitalization, are used to specify the following model:

London $E T F_{t}=\theta_{0}+\theta_{1}$ Index $_{t-1}+\theta_{7} N B P_{t-1}+\theta_{3} F T S E 100_{t-1}+\varepsilon_{t}$

where Index $x_{t-1}$ is the observable price of the equally weighted index at time $t-1$, $N B P_{t-1}$ is the UN NBP natural gas spot price at time $t-1$, FTSE $100_{t-1}$ is the price of FTSE 100 index at time $t-1$, and the random error, which should be distinguished from the return shock, is assumed to be $\varepsilon_{t} \sim \operatorname{iid}\left(0, \sigma_{s}^{2}\right)$.

Combining equations (14) and (15) leads to: 
Index $_{t}=$ London $E T F_{t}+v_{t}$

$=\theta_{0}+\theta_{1}$ Index $_{t-1}+\theta_{7} N B P_{t-1}+\theta_{3}$ FTSE $100_{t-1}+\varepsilon_{t}+v_{t}$

where London ETF refers to London ETF Spot prices. The parameters in equation (16) can be estimated by ordinary least squares (OLS) or Quasi-Maximum Likelihood Estimation (QMLE), depending on the specification of the conditional volatility of the errors, to yield estimates of Index, if the explanatory variables are stationary. As prices are typically non-stationary, there is no reason to expect the error to be conditionally heteroskedastic.

For the reasons given above, estimation of the parameters in equation (16) by OLS yields:

London ETF $_{t}=\widehat{I n d e x}_{t}=\widehat{\theta_{0}}+\widehat{\theta_{1}}$ Index $_{t-1}+\widehat{\theta_{2}} N B P_{t-1}+\widehat{\theta_{3}} F T S E 100_{t-1}$

where the fitted values in equation (17) refer to London ETF Spot prices. As the price of the equally weighted index, NBP, and FTSE 100 at time $t-1$ are already known, estimation of the price of London ETF Spot at time $t$ is obtained by estimating the equally weighted index price at time $t$. Moreover, as the equally weighted index, UK NBP prices, and FTSE 100 are non-stationary, the t-ratios in this case does not have the asymptotic normal distribution. However, it is not problematic as the main purpose of the exercise is to generate the price of London ETF Spot.

As an alternative to OLS, Instrumental Variables (IV) or Generalized Method of Moments (GMM) can be used to estimate the parameters in equation (16) to obtain an estimate of Index, and hence also an estimate of the latent variable, London ETF Spot. However, finding suitable instruments can be problematic when daily data are used. Cointegration analysis might also be used to estimate the parameters in equation (16), but only if consistent estimates of the parameters are desired, and also if statistical inference is intended for the parameter estimates. As we are interested only in the fitted values of Index to generate London ETF Spot, these alternative methods are 
eschewed in favour of the OLS estimates. In view of the definition in equation (14), the estimates of Index will provide estimates of the latent London ETF Spot.

After the price of London ETF Spot is generated, daily time series data on natural gas spot, futures and ETF prices in both USA and UK markets that are to be used for the empirical analysis will all be available. The sample ranges from 14 May 2007 to 15 April 2016, consisting of 2330 observations. The sample size is dictated by the inception date of FCG, 11 May 2007, which was also a Friday. The daily time series data of natural gas spot, futures and FCG are downloaded from the Datastream database, and the prices of FTSE 100 index are downloaded from Yahoo Finance. All the series are expressed in US dollars. The data descriptions are given in Table 4.

\section{[Insert Table 4 here]}

The daily return at time $t$ is calculated as:

$$
r_{t}=100 \times\left\lceil\log \left(P_{t}\right)-\log \left(P_{t-1}\right)\right]
$$

where $P_{t}$ is price at time $t$, and $P_{t-1}$ is the price at time $t-1$. The definitions of the variables are presented in Table 5.

\section{[Insert Table 5 here]}

Figure 4 shows the returns of natural gas spot, futures and EFT prices in the USA and UK. The phenomenon of volatility clustering is obvious, with large volatilities followed by groupings of large volatility, and small volatilities followed by groupings of small volatilities.

\section{[Insert Figure 4 here]}

Table 6 provides the descriptive statistics for the daily returns of natural gas spot, futures and ETF prices. The means of all returns are negative. The Henry Hub natural gas spot market has the highest standard deviation in US markets, followed by the futures market, with the standard deviation of the ETF market being slightly lower in 
comparison. In the UK market, the spot and futures markets have similar standard deviations, while the standard deviation of the ETF market is much lower. In general, the standard deviations of US natural markets are larger than those of the UK.

The returns of natural gas spot and futures markets in both the USA and UK have positive skewness, especially the UK spot and futures markets, where the magnitudes are much larger than in the USA. Positive skewness means those returns have extreme observations in the right tails of the distribution, indicating that natural gas spot and futures market are more likely to incur extreme gains than extreme losses. On the contrary, the ETF markets in both the USA and UK are skewed to left, though with quite small magnitudes.

The value of the kurtosis of all returns are significantly greater than 3 , implying the probability of extreme positive and negative observations in the natural gas spot, futures and ETF markets is larger than for the normal distribution. In particular, the kurtosis of daily returns in the Henry Hub spot, and UK NBP spot and futures markets, is much higher than in the other markets.

The large values of the Jarque-Bera statistics for all the return series signify the non-normal distributions of the variables.

\section{[Insert Table 6 here]}

The results of the unit root tests for daily prices and returns are given in Tables 7 and 8. The Augmented Dicky-Fuller (ADF) and Phillips-Perron (PP) tests are used to test the stability of each return series. As the null hypothesis of both the ADF and PP tests is that the series has a unit root, indicating non-stationarity, a significant result means rejection of the null hypothesis. As can be seen in Tables 7 and 8, the results for the price series are all insignificant, while the results for returns are all significant. Therefore, the six price series are non-stationary, while the return series are all stationary.

\section{[Insert Table 7 here]}




\subsection{Empirical Results}

Partial co-volatility spillover effects may be tested by estimating the weight matrix $A$ in the diagonal BEKK model. If the null hypothesis $H_{0}: a_{i i} \times a_{j j}=0$ is rejected, the value of $a_{i i} \times a_{j j}$ is significantly different from zero, so there will be partial co-volatility spillover effects from market $i$ to $j$. From the definition of co-volatility spillover effects in equation (13), it can be seen that the sizes and signs of the co-volatility spillover effects from market $i$ to $j$ will be determined by the return shock of commodity $j$ at time $t-1$ when $a_{i j}$ and $a_{j j}$ are known.

The testing of co-volatility spillover effects is performed in the following three dimensions:

(1) Co-volatility spillover effects across markets for each country;

(2) Co-volatility spillover effects across markets between the USA and UK;

(3) Co-volatility spillover effects across two countries for each market.

The first dimension tests co-volatility spillovers among natural gas spot, futures and ETF markets in the USA and UK respectively. Specifically, the co-volatility spillover effects among Henry Hub natural gas spot, futures and FCG are tested for the USA; and the co-volatility spillovers among UK NBP natural gas spot, futures and London ETF Spot are tested for the UK. These tests could assist in developing domestic hedging opportunities

In order to discover hedging opportunities internationally, the tests of the second dimension are performed. In particular, the co-volatility spillover effects among the Henry Hub natural gas spot, UK NBP natural gas futures and London ETF Spot markets are tested for hedging opportunities for Henry Hub spot prices; similarly, the co-volatility spillover effects among the UK NBP spot, Henry Hub futures and FCG are examined for UK NBP spot prices.

As to the third dimension, the co-volatility spillover effects between Henry Hub natural gas spot and UK NBP natural gas spot, Henry Hub natural gas futures and UK NBP natural gas futures, and FCG and London ETF Spot are tested to check the 
interactions between specific markets in the USA and UK.

The EViews 8 econometric software package is used for the empirical analysis.

\section{(1) Co-volatility spillover effects across markets for each country}

The empirical results of the VAR (1)-Diagonal BEKK (1,1) model for the US and UK markets are presented in Tables 9 and 10, respectively.

\section{[Insert Tables 9 and 10 here]}

From the estimates of matrix $A$ shown in Table 9, it can be seen that all three coefficients are statistically significant. Such results indicate that there are significant co-volatility spillover effects among the natural gas spot, futures and ETF markets in the USA. The two coefficients, 0.213 and 0.220 , have similar values, while the third coefficient, 0.425, is substantially different from the other two, which implies that the BEKK model for the USA is diagonal.

Table 10 shows that all the estimates of the coefficients in matrix $A$ are significantly different from zero, which suggests the existence of significant co-volatility spillover effects among the NBP spot, futures and London ETF Spot markets. The value of 0.173 is quite different the other two, at 0.420 and 0.417 . The BEKK model for the UK is also diagonal, but has different coefficient weights in matrix $A$ comparing its counterpart for the USA. The range of the coefficients in matrix $A$ is 0.212 (= 0.425 $0.213)$ in the USA and $0.247(=0.420-0.173)$ in the UK, which are similar.

Tables 9 and 10 also show the mean return shocks for each market in the two countries. In both the USA and UK, the Henry Hub spot market is the only one that has positive mean return shocks. Comparing the absolute values of mean return shocks shows that the return shocks in US markets are greater than in UK markets, and the market that has largest absolute mean return shocks is FCG.

Table 11 gives the partial co-volatility spillover effects for the USA and UK. In the USA, both positive and negative co-volatility spillovers exist. Return shocks from 
Henry Hub spot prices have negative spillover effects on subsequent Henry Hub futures prices, while Henry Hub futures prices have positive spillover effects on subsequent Henry Hub spot prices. When comparing the absolute value of co-volatility spillover effects, Henry Hub spot markets have greater effects than do Henry Hub futures markets. It is clear that the co-volatility spillover effects between the Henry Hub spot and futures markets are asymmetric, with negative return shocks having greater impacts on co-volatility than positive return shocks of the same magnitude.

The situation between Henry Hub spot prices and FCG prices are similar, with asymmetric co-volatility spillover effects. The co-volatility spillover effects between the Henry Hub futures market and FCG markets are both negative. In the UK, all the co-volatility spillover effects are negative, implying no asymmetry. In particular, the co-volatility spillovers between the UK NBP spot and futures prices not only have the same signs but also approximately the same magnitudes. The case of the NBP futures and London ETF Spot markets are similar. Both the return shocks from the NBP spot and London ETF Spot markets have negative impacts on their respective co-volatilities, but the impact from NBP spot is greater than from London ETF Spot.

\section{[Insert Table 11 here]}

In general, there are significant co-volatility spillover effects among natural gas spot, futures and ETF markets in both USA and UK. Hedging opportunities can be found both between Henry Hub spot and futures markets and between Henry Hub spot and FCG markets.

\section{(2) Volatility spillovers across markets between two countries}

Tables 12 and 13 show the empirical results of the VAR (1)-Diagonal BEKK $(1,1)$ model for the Henry Hub spot and UK NBP spot markets.

\section{[Insert Tables 12 and 13 here]}

In Table 12, the three coefficients of matrix A, 0.364, 0.297 and 0.163 , are all different 
from each other, indicating that BEKK is diagonal. The estimates of $A$ in Table 13 are $0.295,0.211$ and 0.228 , where 0.295 is the largest and differs from other two. The estimated BEKK model is also diagonal in Table 13. Unlike the results of the first dimension, the range and weights of the coefficients of the matrix $A$ in Tables 12 and 13 are different. As in Tables 9 and 10, the Henry Hub spot market is the only one that has positive mean return shocks, while the FCG market still has the largest absolute mean return shocks.

The co-volatility spillover effects are shown in Table 14. The results in this dimension are similar to the first dimension, namely the co-volatility spillover effects between the Henry Hub spot and UK NBP futures, and Henry Hub spot and London ETF Spot, are both asymmetric, thereby suggesting opportunities for hedging.

\section{[Insert Table 14 here]}

Co-volatility spillover effects also exist between the spot and futures markets, as well as between the ETF markets between the two countries.

\section{(3) Volatility spillovers across two countries for each market}

The co-volatility spillover effects across three kinds of US and UK natural gas markets, namely the spot, futures and ETF markets, are obtained using the VAR (1)-Diagonal BEKK $(1,1)$ model, as given in Tables 15-17 respectively.

\section{[Insert Tables 15 - 17 here]}

The estimates of matrix $A$ in Table 15 show that two coefficients are significant, but with different values. Such results indicate a diagonal BEKK model for the spot market. The mean return shocks in the Henry Hub spot market are still the only one that is positive. Table 16 also shows two significant and different coefficients, at 0.228 and 0.303 . There are no positive mean return shocks in either the UK NBP spot or futures markets. The results shown in Table 17 are similar to those in Table 16. Comparing the estimates of matrix $A$ in the three markets, the ranges are similar, while the weights are distinctly different. 
The partial co-volatility spillover effects are given in Table 18. In the natural gas spot markets, the co-volatility spillover effects have similar absolute values, but with different signs. The return shocks in the Henry Hub spot market at $t-1$ have a negative impact on the co-volatility between the Henry Hub spot return and UK NBP spot return at time $t$, while the co-volatility spillover effects from the UK NBP spot market have positive impacts on the Henry Hub spot market.

The co-volatility spillovers effects between the Henry Hub futures market and UK NBP futures market are both negative. The empirical results for the US and UK natural gas ETF markets are similarly negative as that for the natural gas futures markets.

\section{[Insert Table 18 here]}

In summary, there are significant co-volatility spillovers between the USA and UK natural gas for the spot, futures and ETF markets. The asymmetry of co-volatility spillover effects between the Henry Hub spot and UK NBP spot markets suggests opportunities for hedging. The absolute values of the co-volatility spillover effects indicates that UK markets have greater impacts on USA markets than the reverse.

\section{Conclusion}

The paper tested and calculated spillover effects among natural gas spot, futures and ETF markets in both the USA and UK using the diagonal BEKK multivariate conditional volatility model. Data used for the empirical analysis ranges from 14 May 2007 to 15 April 2016, incorporating 2330 observations.

The empirical analysis is presented in three dimensions:

(1) Co-volatility spillover effects across markets for each country;

(2) Co-volatility spillover effects across markets between the USA and UK;

(3) Co-volatility spillover effects across two countries for each market. 
For the first dimension, it is obvious that there are spillover effects among the natural gas spot, futures and ETF markets in both the USA and UK. In the USA, opportunities exist between the spot and futures markets, and between the spot and ETF markets.

In order to search for hedging opportunities abroad, tests of the second dimension are performed. The empirical analysis shows that hedging opportunities also arise between the spot market in the USA and futures market in the UK, simultaneously with the spot market in the USA and ETF market in the UK.

For the third dimension, the empirical results show that there are significant spillover effects between natural gas markets in the USA and UK, including between the spot, futures and ETF markets.

As the co-volatility spillover effects between the spot markets in the USA and UK are asymmetric, there are hedging opportunities between the two markets.

It is clear that there are significant co-volatility spillover effects in the natural gas spot, futures and ETF markets for both the USA and UK, which means that world natural gas markets are highly correlated. Interestingly, spot and futures prices across countries are useful for purposes of constructing optimal dynamic hedging strategies, and similarly for ETF. 


\section{References}

Amemiya, T. (1985), Advanced Econometrics, Harvard University Press, Cambridge, MA.

Baba, Y., R.F. Engle, D. Kraft and K.F. Kroner (1985), "Multivariate simultaneous generalized ARCH,” Unpublished manuscript, Department of Economics, University of California, San Diego, CA.

Bollerslev, T. (1986), “Generalised autoregressive conditional heteroscedasticity,” Journal of Econometrics, 31, 307-327.

Bollerslev, T. (1990), "Modelling the coherence in short-run nominal exchange rate: A multivariate generalized ARCH approach,” Review of Economics and Statistics, 72, 498-505.

Caporin, M. and M. McAleer (2008), "Scalar BEKK and indirect DCC,” Journal of Forecasting, 27(6), 537-549.

Caporin, M. and M. McAleer (2012), "Do we really need both BEKK and DCC? A tale of two multivariate GARCH models,” Journal of Economic Surveys, 26(4), 736-751.

Chang, C.-L., T.-L. Hsieh and M. McAleer (2016), "How are VIX and stock index ETF related,” Tinbergen Institute Discussion Paper 010/III.

Chang, C.-L. and Y.-P. Ke (2014), “Testing Price Pressure, Information, Feedback Trading, and Smoothing Effects for Energy Exchange Traded Funds," Annals of Financial Economics, 9(2), 1-26. 
Chang, C.-L., Y.-Y. Li and M. McAleer, (2015), "Volatility spillovers between energy and agricultural markets: A critical appraisal of theory and practice,” Tinbergen Institute Discussion Paper 077/III.

Chang, C.-L., M. McAleer, and R. Tansuchat (2011), “Crude oil hedging strategies using dynamic multivariate GARCH,” Energy Economics, 33(5), 912-923.

Chang, C.-L., M. McAleer and R. Tansuchat (2010), “Analyzing and forecasting volatility spillovers, asymmetries and hedging in major oil markets," Energy Economics, 32, 1445-1455.

Chang, C.-L., M. McAleer and Y.-A. Wang (2016), "Modelling volatility spillovers for bio-ethanol, sugarcane and corn,” Tinbergen Institute Discussion Paper 014/III.

Chen, J.-H. (2011), “The spillover and leverage effects of ethical exchange traded fund,” Applied Economics Letters, 18(10), 983-987.

Chen, J.-H. and C.-Y. Huang (2010), “An analysis of the spillover effects of exchange traded funds,” Applied Economics, 42(9), 1155-1168.

Efimova, O. and A. Serletis (2014), "Energy markets volatility modelling using GARCH,” Energy Economics, 43, 264-273

Engle, R.F. (1982), “Autoregressive conditional heteroscedasticity with estimates of the variance of United Kingdom inflation,” Econometrica, 50, 987-1007.

Engle, R.F. (2002), “Dynamic conditional correlation: A simple class of multivariate generalized autoregressive conditional hereoskedasticity models,” Journal of Business and Economic Statistics, 20, 339-350.

Engle, R.F. and K.F. Kroner (1995), “Multivariate simultaneous generalized ARCH,” Econometric Theory, 11, 122-150. 
Ewing, B., F. Malik and O. Ozfiden (2002), "Volatility transmission in the oil and natural gas markets,” Energy Economics, 24, 525-538.

Hafner, C. and M. McAleer (2014), “A one line derivation of DCC: Application of a vector random coefficient moving average process,” Tinbergen Institute Discussion Paper, 14-087, The Netherlands.

Haigh, M.S. and M. Holt (2002), “Crack spread hedging: Accounting for time-varying spillovers in the energy futures markets,” Journal of Applied Econometrics, 17, 269-289.

Hammoudeh, S., H. Li, and B. Jeon (2003), “Causality and volatility spillovers among petroleum prices of WTI, gasoline and heating oil," North American Journal of Economics and Finance 14, 89-114.

Jeantheau, T. (1998), "Strong consistency of estimators for multivariate ARCH models,” Econometric Theory, 14, 70-86.

Karali, B. and O.A. Ramirez (2014), "Macro determinants of volatility and volatility spillover in energy market,” Energy Economics , 46, 413-421.

Krause, T. and Y. Tse (2013), "Volatility and return spillovers in Canadian and U.S. industry ETFs,” International Review of Economics and Finance, 25, 244-259.

Ling, S. and M. McAleer (2003), “Asymptotic theory for a vector ARMA-GARCH model,” Econometric Theory, 19, 278-308.

Lin, S. and M. Tamvakis (2001), "Spillover effects in energy futures markets,” Energy Economics, 23, 43-56.

McAleer, M. (2005), “Automated inference and learning in modeling financial volatility,” Econometric Theory, 21(1), 232-261. 
McAleer, M. (2014), “Asymmetry and leverage in conditional volatility models,” Econometrics, 2(3), 145-150.

McAleer, M., F. Chan, S. Hoti and O. Lieberman (2008), “Generalized autoregressive conditional correlation”, Econometric Theory, 24(6), 1554-1583.

McAleer, M., S. Hoti and F. Chan (2009), "Structure and asymptotic theory for multivariate asymmetric conditional volatility”, Econometric Reviews, 28, 422-440.

Milunovich, G. and S. Thorp (2006), "Valuing volatility spillovers,” Global Finance Journal, 17, 1-22.

Sadorsky, P. (2012), "Correlations and volatility spillovers between oil prices and the stock prices of clean energy and technology companies,” Energy Economics, 34, 248-255.

Tse, Y.K. and A.K.C. Tsui (2002), “A multivariate GARCH model with time-varying correlations,” Journal of Business and Economic Statistics, 20, 351-362.

Tsay, R.S. (1987), “Conditional heteroscedastic time series models,” Journal of the American Statistical Association, 82, 590-604. 
Figure 1: Primary Energy Consumption by Fuel in the USA

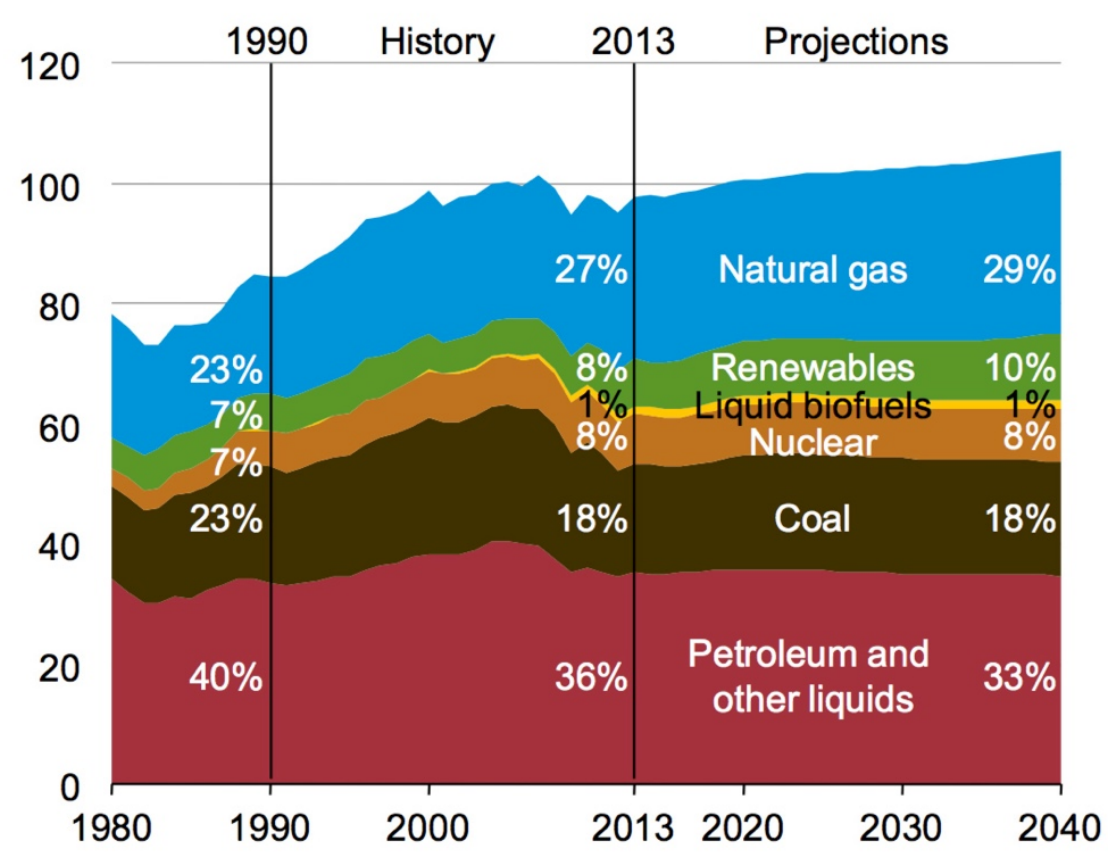

Figure 2: Electricity Generation by Fuel in the USA

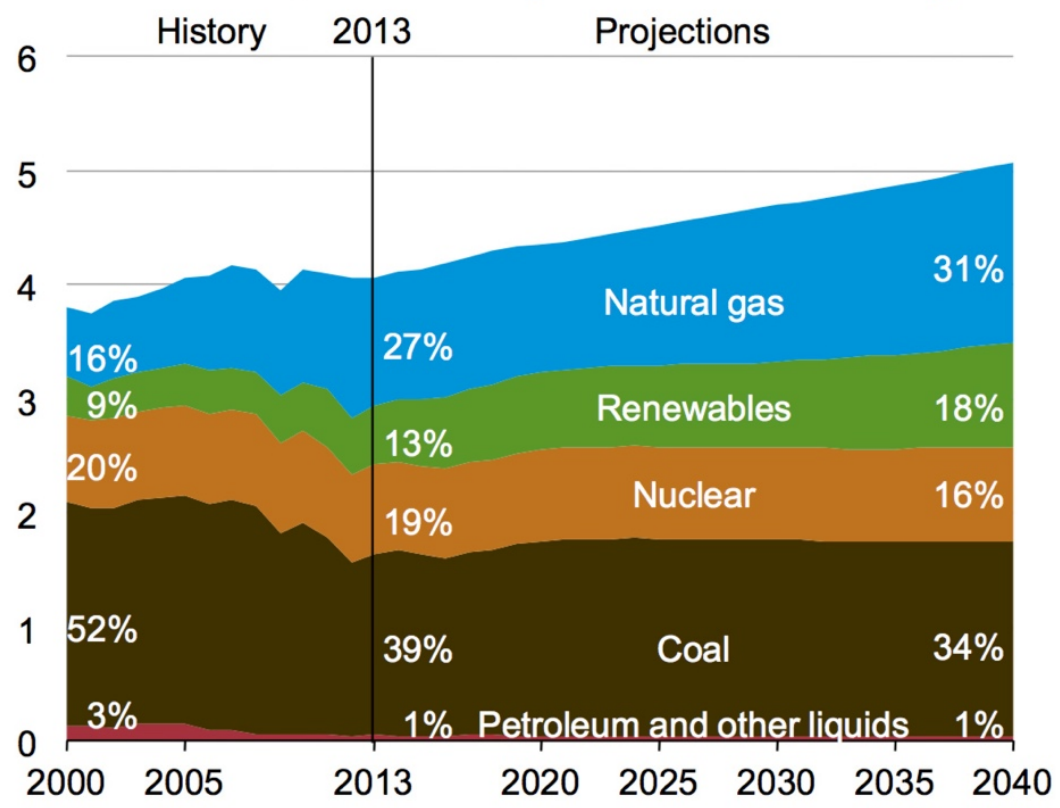


Figure 3: Natural Gas Spot Prices from February 3, 1997 to April 15, 2016
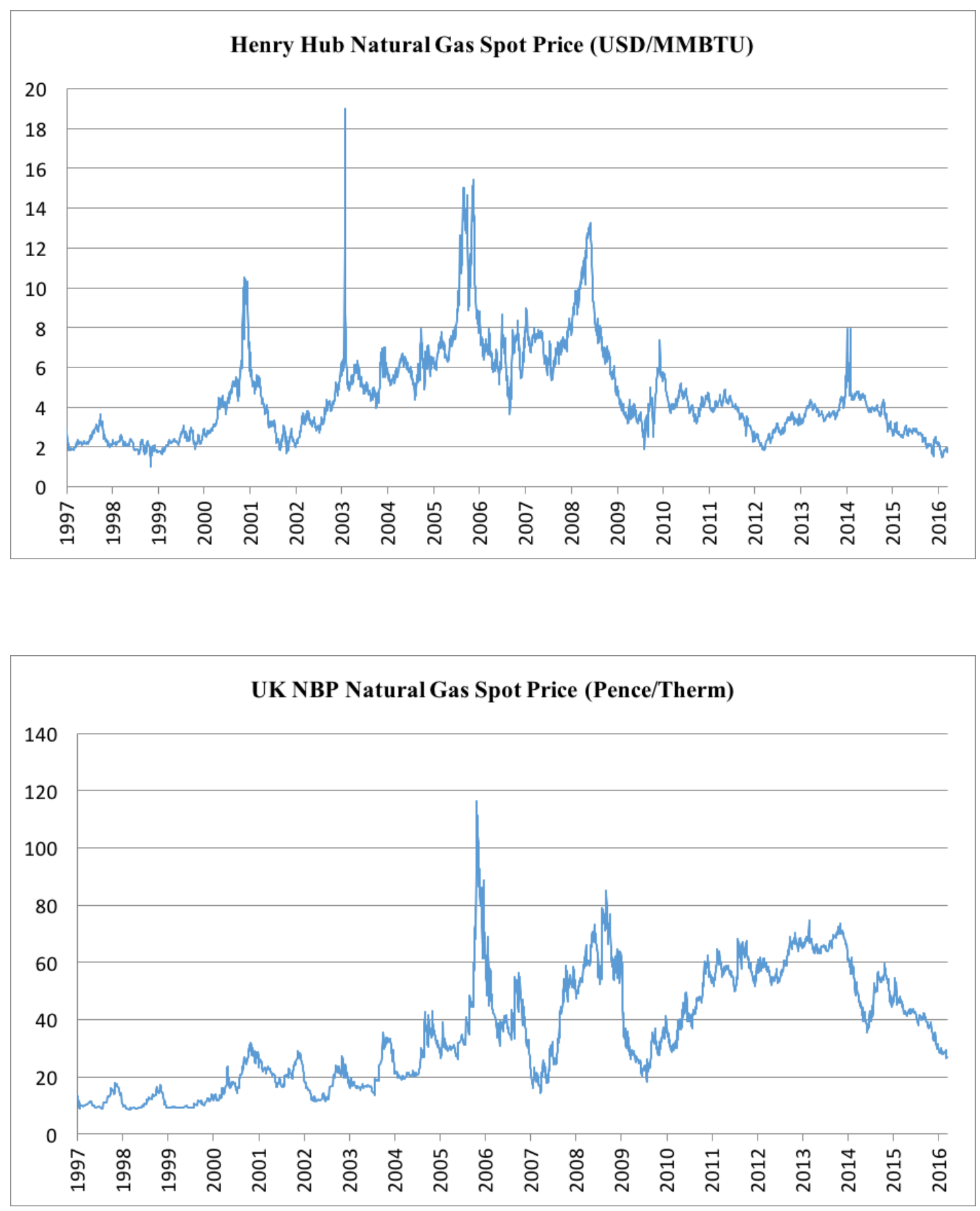
Figure 4: Natural Gas Spot, Futures and ETF Spot Returns
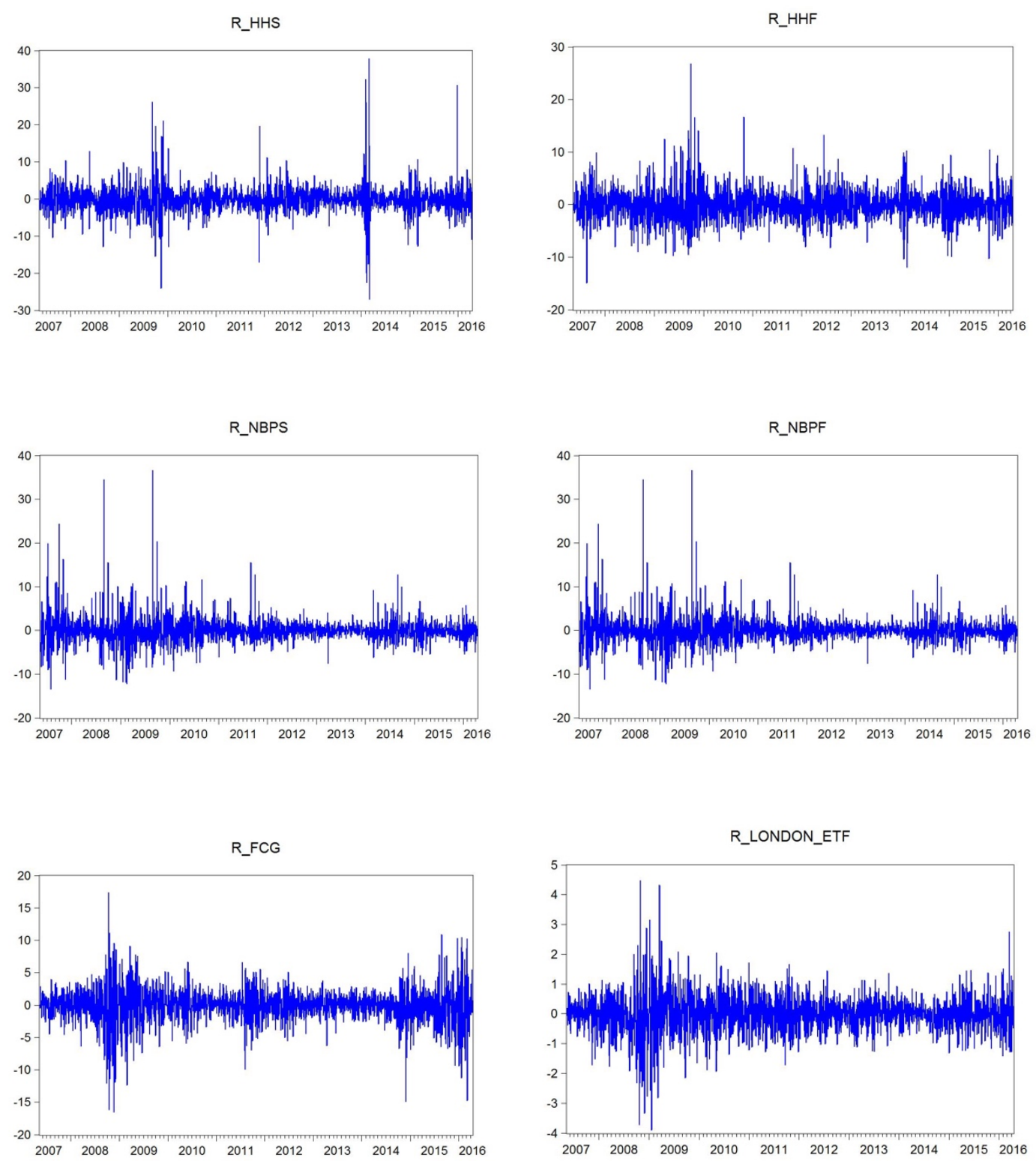
Table 1: Top 20 Energy Futures and Options Contracts in 2014

\begin{tabular}{clc}
\hline Rank & Contract & Trading volume (\$) \\
\hline 1 & Brent Crude Futures & $160,425,461$ \\
2 & Light, Sweet Crude Oil Futures, & $145,147,334$ \\
3 & Henry Hub Natural Gas Futures & $74,206,602$ \\
4 & Coke Futures & $63,688,294$ \\
5 & Coking Coal Futures & $57,605,436$ \\
6 & Gasoil Futures & $52,800,084$ \\
7 & NY Harbor RBOB Gasoline Futures & $34,421,866$ \\
8 & No. 2 Heating Oil Futures & $33,946,420$ \\
9 & WTI Crude Futures & $31,600,959$ \\
10 & Crude Oil (LO) Options & $31,107,783$ \\
11 & Natural Gas European-Style Options & $20,936,070$ \\
12 & Crude Oil Futures & $20,731,880$ \\
13 & Brent Crude Oil Last Day Futures & $18,493,384$ \\
14 & U.S. Oil Fund ETF Options & $16,492,138$ \\
15 & Natural Gas Futures & $15,628,773$ \\
16 & Brent Crude Opt. on Fut. & $13,285,768$ \\
17 & U.S. Natural Gas Fund ETF Options & $9,254,832$ \\
18 & Brent Oil Futures & $7,084,451$ \\
19 & EUA Futures & $7,008,526$ \\
20 & Henry Hub Swap (NN) Futures & $6,332,365$ \\
\hline & &
\end{tabular}


Table 2: Component Companies of ISE-Revere Natural Gas Index

\begin{tabular}{cl}
\hline No. & Company Name \\
\hline 1 & Anadarko Petroleum Corporation \\
2 & Antero Resources Corporation \\
3 & Apache Corporation \\
4 & Cabot Oil \& Gas Corporation \\
5 & Cimarex Energy Co. \\
7 & Columbia Pipeline Group Inc \\
8 & Concho Resources Inc. \\
9 & Devon Energy Corporation \\
10 & Diamondback Energy, Inc. \\
11 & Golar Lorporation Limited \\
12 & Gulfport Energy Corporation \\
13 & Hess Corporation \\
14 & Kinder Morgan Inc Class P \\
15 & Marathon Oil Corporation \\
16 & Matador Resources Company \\
17 & Memorial Resource Development Corp \\
18 & Murphy Oil Corporation \\
19 & Newfield Exploration Company \\
20 & Noble Energy, Inc. \\
21 & PDC Energy Inc \\
22 & Pioneer Natural Resources Company \\
23 & QEP Resources, Inc. \\
24 & Range Resources Corporation \\
25 & Rice Energy Inc. \\
26 & SM Energy Company \\
27 & Southwestern Energy Company \\
28 & Spectra Energy Corp \\
29 & Statoil ASA \\
30 & Synergy Resources Corporation \\
31 & WPX Energy, Inc. Class A \\
\hline
\end{tabular}


Table 3: List of Selected UK Natural Gas Companies

\begin{tabular}{|c|c|c|c|c|}
\hline Company & Market & Sector & $\begin{array}{c}\text { Country of } \\
\text { Incorporation }\end{array}$ & $\begin{array}{c}\text { Market Cap } \\
\text { (million } \\
\text { GBP) }\end{array}$ \\
\hline $\mathrm{BP}$ & Main Market & $\begin{array}{l}\text { oil \& gas } \\
\text { producers }\end{array}$ & UK & 6736.87 \\
\hline $\begin{array}{l}\text { Royal Dutch } \\
\text { Shell "B" }\end{array}$ & Main Market & $\begin{array}{l}\text { oil \& gas } \\
\text { producers }\end{array}$ & UK & 53411.09 \\
\hline Cairn Energy & Main Market & $\begin{array}{l}\text { oil \& gas } \\
\text { producers }\end{array}$ & UK & 1156.56 \\
\hline Faroe Petroleum & AIM & $\begin{array}{l}\text { oil \& gas } \\
\text { producers }\end{array}$ & UK & 193.58 \\
\hline $\begin{array}{l}\text { Parkmead } \\
\text { Group }\end{array}$ & AIM & $\begin{array}{l}\text { oil \& gas } \\
\text { producers }\end{array}$ & UK & 57.38 \\
\hline IGas Energy & AIM & $\begin{array}{l}\text { oil \& gas } \\
\text { producers }\end{array}$ & UK & 56.92 \\
\hline
\end{tabular}

\section{Notes:}

1. Main Market is London Stock Exchange’s flagship market for larger, more established companies.

2. AIM is the London Stock Exchange's international market for smaller growing companies. 
Table 4: Data Sources

\begin{tabular}{|c|c|c|}
\hline Source & Transaction market & Description \\
\hline $\begin{array}{l}\text { Henry Hub Natural } \\
\text { Gas Spot }\end{array}$ & $\begin{array}{l}\text { New York Mercantile } \\
\text { Exchange (NYMEX) }\end{array}$ & $\begin{array}{l}\text { Natural Gas-Henry Hub Price } \\
\text { (US dollar per Million Btu) }\end{array}$ \\
\hline $\begin{array}{l}\text { Henry Hub Natural } \\
\text { Gas Futures }\end{array}$ & $\begin{array}{l}\text { New York Mercantile } \\
\text { Exchange (NYMEX) }\end{array}$ & $\begin{array}{l}\text { NYMEX Henry Hub Natural } \\
\text { Gas Futures Continuous } \\
\text { Settlement Price } \\
\text { (US dollar per Million Btu) }\end{array}$ \\
\hline FCG & $\begin{array}{l}\text { New York Stock Exchange } \\
\text { Arca (NYSE Arca) }\end{array}$ & $\begin{array}{l}\text { First Trust ISE-Revere } \\
\text { Natural Gas Index Fund } \\
\text { Price } \\
\text { (US dollar) }\end{array}$ \\
\hline $\begin{array}{l}\text { UK NBP Natural Gas } \\
\text { Spot }\end{array}$ & $\begin{array}{l}\text { Intercontinental Exchange } \\
\text { (ICE) }\end{array}$ & $\begin{array}{l}\text { ICE Natural Gas 1Month } \\
\text { Forward Price } \\
\text { (Pence per Therm) }\end{array}$ \\
\hline $\begin{array}{l}\text { UK Natural Gas } \\
\text { Daily Futures }\end{array}$ & $\begin{array}{l}\text { Intercontinental Exchange } \\
\text { (ICE) }\end{array}$ & $\begin{array}{l}\text { ICE UK Natural Gas Daily } \\
\text { Futures Continuous } \\
\text { Settlement Price } \\
\text { (Pence per Therm) }\end{array}$ \\
\hline FTSE 100 Index & Can not be traded & $\begin{array}{l}\text { The Financial Times Stock } \\
\text { Exchange } 100 \text { Index } \\
\text { (Pound) }\end{array}$ \\
\hline London ETF Spot & $\begin{array}{l}\text { The spot stocks it tracks } \\
\text { can be traded in London } \\
\text { Stock Exchange (LSE) }\end{array}$ & $\begin{array}{l}\text { Self-defined Natural Gas } \\
\text { ETF Spot in London Market } \\
\text { (Pound) }\end{array}$ \\
\hline
\end{tabular}


Table 5: Definitions of Variables

\begin{tabular}{|c|c|}
\hline Variable & Definition \\
\hline HHS & Daily price of Henry Hub natural gas spot \\
\hline$H H F$ & Daily price of Henry Hub natural gas futures \\
\hline$F C G$ & Daily price of USA natural gas ETF \\
\hline NBPS & Daily price of UK NBP natural gas spot \\
\hline NBPF & Daily price of UK NBP natural gas futures \\
\hline London ETF & Daily price of UK natural gas ETF spot \\
\hline$r_{H H S}$ & Daily price return of Henry Hub natural gas spot \\
\hline$r_{H H F}$ & Daily price return of Henry Hub natural gas futures \\
\hline$r_{F C G}$ & Daily price return of USA natural gas ETF \\
\hline$r_{N R P S}$ & Daily price return of UK NBP natural gas spot \\
\hline$r_{N B P F}$ & Daily price return of UK NBP natural gas futures \\
\hline$r_{\text {I., nndon FTF }}$ & Daily price return of UK natural gas ETF spot \\
\hline
\end{tabular}

Note: London ETF Spot is a generated variable. 
Table 6: Descriptive Statistics

\begin{tabular}{cccccccc}
\hline Returns & Mean & SD & Max & Min & Skewness & Kurtosis & Jarque-Bera \\
\hline$r_{H H . S}$ & -0.065 & 3.704 & 37.815 & -27.018 & 0.919 & 19.530 & 26842.76 \\
$r_{H H F}$ & -0.061 & 3.043 & 26.771 & -14.893 & 0.653 & 7.773 & 2376.199 \\
$r_{F C C_{1}}$ & -0.064 & 2.629 & 17.336 & -16.551 & -0.412 & 8.057 & 2547.737 \\
$r_{N B P S}$ & -0.013 & 2.967 & 36.624 & -13.466 & 2.250 & 26.799 & 56931.37 \\
$r_{N B P F}$ & -0.013 & 2.959 & 36.624 & -13.466 & 2.276 & 27.058 & 58176.77 \\
$r_{l ., n d o n F T F}$ & -0.011 & 0.627 & 4.477 & -3.911 & -0.030 & 8.011 & 2437.007 \\
\hline
\end{tabular}

Note: London ETF Spot is a generated variable. The Jarque-Bera Lagrange Multiplier test is asymptotically chi-squared, and is based on testing skewness and kurtosis against the normal distribution. 
Table 7: Unit Root Test for Prices

\begin{tabular}{cccc}
\hline & \multicolumn{3}{c}{ ADF test } \\
\cline { 2 - 4 } Variables & No trend and intercept & With intercept & With trend and intercept \\
\hline HHS & -1.522 & -1.939 & -2.524 \\
HHF & -1.569 & -1.856 & -2.380 \\
FCG & -1.093 & -1.028 & -1.738 \\
NBPS & -0.732 & -2.123 & -2.215 \\
NBPF & -0.731 & -2.118 & -2.210 \\
London ETF & -1.063 & -2.061 & -2.084 \\
\hline & & PP test & \\
Variables & No trend and intercept & With intercept & With trend and intercept \\
\hline HHS & -1.567 & -1.971 & -2.503 \\
HHF & -1.579 & -1.797 & -2.313 \\
FCG & -1.094 & -1.028 & -1.728 \\
NBPS & -0.688 & -1.976 & -2.067 \\
NBPF & -0.687 & -1.974 & -2.065 \\
London $E T F$ & -1.073 & -2.051 & -2.073 \\
\hline
\end{tabular}

Notes:

1. None is significant at standard levels.

2. London ETF Spot is a generated variable. 
Table 8: Unit Root Test for Returns

\begin{tabular}{|c|c|c|c|}
\hline \multirow[b]{2}{*}{ Variables } & \multicolumn{3}{|c|}{ ADF test } \\
\hline & No trend and intercept & With intercept & With trend and intercept \\
\hline$r_{H H S}$ & $-31.933^{*}$ & $-31.946^{*}$ & $-31.940 *$ \\
\hline$r_{H H F}$ & $-52.517^{*}$ & $-52.528 *$ & $-52.517 *$ \\
\hline$r_{F C r_{i}}$ & $-49.173^{*}$ & $-49.193^{*}$ & $-49.225^{*}$ \\
\hline$r_{N R P S}$ & $-30.450 *$ & $-30.444^{*}$ & $-30.493^{*}$ \\
\hline$r_{N R P F}$ & $-30.437^{*}$ & $-30.432 *$ & $-30.481 *$ \\
\hline \multirow[t]{2}{*}{$r_{\text {I.nndon FTF }}$} & $-46.422 *$ & $-46.426^{*}$ & $-46.418 *$ \\
\hline & \multicolumn{3}{|c|}{ PP test } \\
\hline Variables & No trend and intercept & With intercept & With trend and intercept \\
\hline$r_{H H .}$ & $-44.153^{*}$ & $-44.204^{*}$ & $-44.195 *$ \\
\hline$r_{H H F}$ & $-52.609 *$ & $-52.632 *$ & $-52.621^{*}$ \\
\hline$r_{F C r}$ & $-49.222^{*}$ & $-49.252 *$ & $-49.321 *$ \\
\hline$r_{N R P S}$ & $-47.112 *$ & $-47.102 *$ & $-47.148 *$ \\
\hline$r_{N B P F}$ & $-46.883^{*}$ & $-46.874^{*}$ & $-46.918 *$ \\
\hline$r_{\text {Inndon FTF }}$ & $-46.396 *$ & $-46.401 *$ & $-46.393 *$ \\
\hline
\end{tabular}

Notes:

1. * denotes $1 \%$ level.

2. London ETF Spot is a generated variable. 
Table 9: Diagonal BEKK for USA

\begin{tabular}{cccc}
\hline VAR(1) & $\boldsymbol{r}_{H H S}$ & $\boldsymbol{r}_{H H F}$ & $\boldsymbol{r}_{F C F}$ \\
\hline \multirow{2}{*}{$r_{H H S}(-1)$} & 0.016 & $0.037^{*}$ & 0.016 \\
& $(0.019)$ & $(0.017)$ & $(0.015)$ \\
$r_{H H F}(-1)$ & $0.519^{* *}$ & $-0.103^{* *}$ & -0.015 \\
& $(0.024)$ & $(0.022)$ & $(0.019)$ \\
$r_{F C C_{1}}(-1)$ & 0.003 & 0.034 & -0.017 \\
& $(0.028)$ & $(0.025)$ & $(0.022)$ \\
$C$ & -0.032 & -0.063 & -0.065 \\
& $(0.069)$ & $(0.063)$ & $(0.055)$ \\
\hline
\end{tabular}

\begin{tabular}{|c|c|c|c|c|}
\hline BEKK & & $A$ & & $\overline{\varepsilon_{i}}$ \\
\hline$r_{H H S}$ & $\begin{array}{c}0.425^{* *} \\
(0.011)\end{array}$ & \multirow{3}{*}{$\begin{array}{c}0.213 * * \\
(0.011)\end{array}$} & & 0.016 \\
\hline$r_{H H F}$ & & & & -0.061 \\
\hline$r_{F C C_{1}}$ & & & $\begin{array}{c}0.220 * * \\
(0.010)\end{array}$ & -0.105 \\
\hline
\end{tabular}

\section{Notes:}

1. $A=\left[\begin{array}{ccc}a_{11} & 0 & 0 \\ 0 & a_{22} & 0 \\ 0 & 0 & a_{33}\end{array}\right]$

2. $\bar{\varepsilon}_{\mathrm{i}}$ is the mean return shock.

3. * denotes $5 \%$ level; ** denotes $1 \%$ level.

4. Standard errors are given in parentheses. 
Table 10: Diagonal BEKK for UK

\begin{tabular}{|c|c|c|c|}
\hline VAR(1) & $r_{N R P S}$ & $r_{N R P F}$ & $r_{\text {IOndon ETF }}$ \\
\hline$r_{N R P S}(-1)$ & $\begin{array}{l}-0.817^{*} \\
(0.327)\end{array}$ & $\begin{array}{l}-0.317 \\
(0.327)\end{array}$ & $\begin{array}{c}0.105 \\
(0.069)\end{array}$ \\
\hline$r_{N R P F}(-1)$ & $\begin{array}{c}0.849 * * \\
(0.328)\end{array}$ & $\begin{array}{c}0.348 \\
(0.327)\end{array}$ & $\begin{array}{l}-0.109 \\
(0.069)\end{array}$ \\
\hline$r_{\text {l.nndon FTF }}(-1)$ & $\begin{array}{l}-0.075 \\
(0.101)\end{array}$ & $\begin{array}{l}-0.057 \\
(0.101)\end{array}$ & $\begin{array}{l}0.043^{*} \\
(0.021)\end{array}$ \\
\hline$C$ & $\begin{array}{l}-0.012 \\
(0.061)\end{array}$ & $\begin{array}{c}-0.012 \\
(0.061) \\
\end{array}$ & $\begin{array}{c}-0.011 \\
(0.013) \\
\end{array}$ \\
\hline
\end{tabular}

\begin{tabular}{|c|c|c|c|}
\hline BEKK & $A$ & & $\overline{\widehat{\varepsilon_{i}}}$ \\
\hline$r_{N R P S}$ & $\begin{array}{c}0.420 * * \\
(0.010)\end{array}$ & & -0.015 \\
\hline$r_{N R P F}$ & $\begin{array}{l}0.417^{* *} \\
(0.009)\end{array}$ & & -0.011 \\
\hline$r_{\text {l.nndon FTF }}$ & & $\begin{array}{c}0.173 * * \\
(0.009)\end{array}$ & -0.007 \\
\hline
\end{tabular}

\section{Notes:}

1. $A=\left[\begin{array}{ccc}a_{11} & 0 & 0 \\ 0 & a_{22} & 0 \\ 0 & 0 & a_{33}\end{array}\right]$

2. $\bar{\varepsilon}_{i}$ is the mean return shock.

3. * denotes $5 \%$ level; ** denotes $1 \%$ level.

4. Standard errors are given in parentheses.

5. London ETF Spot is a generated variable. 
Table 11: Co-Volatility Spillovers for USA and UK

\begin{tabular}{|c|c|c|c|}
\hline Country & $i$ & $j$ & Mean Co-volatility Spillovers $\left(\partial Q_{i j t} / \partial \varepsilon_{i t-1}\right)$ \\
\hline \multirow{6}{*}{ USA } & $r_{H H S}$ & $r_{H H F}$ & $0.425 \times 0.213 \times(-0.061)=-0.0055$ \\
\hline & $r_{H H F}$ & $r_{H H S}$ & $0.425 \times 0.213 \times 0.016=0.0014$ \\
\hline & $r_{H H . S}$ & $r_{F C f_{\mathrm{t}}}$ & $0.425 \times 0.220 \times(-0.105)=-0.009 \varepsilon$ \\
\hline & $r_{F C f}$ & $r_{H H S}$ & $0.425 \times 0.220 \times 0.016=0.0015$ \\
\hline & $r_{H H F}$ & $r_{F C G}$ & $0.213 \times 0.220 \times(-0.105)=-0.004 \mathrm{C}$ \\
\hline & $r_{F C C_{1}}$ & $r_{H H F}$ & $0.213 \times 0.220 \times(-0.061)=-0.002 C$ \\
\hline \multirow{6}{*}{ UK } & $r_{N B P S}$ & $r_{N R P F}$ & $0.420 \times 0.417 \times(-0.011)=-0.001 \mathrm{C}$ \\
\hline & $r_{N R P F}$ & $r_{N R P S}$ & $0.420 \times 0.417 \times(-0.015)=-0.002 \epsilon$ \\
\hline & $r_{N B P S}$ & $r_{\text {london FTF }}$ & $0.420 \times 0.173 \times(-0.007)=-0.0005$ \\
\hline & $r_{\text {l.nndom FTF }}$ & $r_{N R P S}$ & $0.420 \times 0.173 \times(-0.015)=-0.0011$ \\
\hline & $r_{N B P F}$ & $r_{\text {l.ondon FTF }}$ & $0.417 \times 0.173 \times(-0.007)=-0.0005$ \\
\hline & $r_{\text {london FTF }}$ & $r_{N R P F}$ & $0.417 \times 0.173 \times(-0.011)=-0.000 \varepsilon$ \\
\hline
\end{tabular}

\section{Notes:}

1. Co-volatility spillovers are from market $i$ to $j$.

2. London ETF Spot is a generated variable. 
Table 12: Diagonal BEKK for Hedging Henry Hub Spot

\begin{tabular}{|c|c|c|c|c|}
\hline VAR(1) & $r_{H H S}$ & & $r_{N R P F}$ & $r_{\text {IOndon FTF }}$ \\
\hline$r_{H H S}(-1)$ & $\begin{array}{l}0.097 * \\
(0.021)\end{array}$ & & $\begin{array}{c}-0.004 \\
(0.017)\end{array}$ & $\begin{array}{c}0.003 \\
(0.004)\end{array}$ \\
\hline$r_{N R P F}(-1)$ & $\begin{array}{c}0.023 \\
(0.027)\end{array}$ & & $\begin{array}{c}0.032 \\
(0.022)\end{array}$ & $\begin{array}{c}-0.004 \\
(0.005)\end{array}$ \\
\hline$r_{\text {l.ondon FTF }}(-1)$ & $\begin{array}{c}0.027 \\
(0.126)\end{array}$ & & $\begin{array}{c}-0.056 \\
(0.101)\end{array}$ & $\begin{array}{c}0.042 \\
(0.021)\end{array}$ \\
\hline$C$ & $\begin{array}{c}-0.058 \\
(0.076) \\
\end{array}$ & & $\begin{array}{c}-0.012 \\
(0.061)\end{array}$ & $\begin{array}{c}-0.010 \\
(0.013)\end{array}$ \\
\hline BEKK & \multicolumn{3}{|c|}{$A$} & $\overline{\widehat{\varepsilon_{i}}}$ \\
\hline$r_{H H S}$ & $\begin{array}{l}0.364^{*} \\
(0.013)\end{array}$ & \multirow{3}{*}{$\begin{array}{l}0.297 * \\
(0.006)\end{array}$} & & 0.037 \\
\hline$r_{N R P F}$ & & & & -0.016 \\
\hline$r_{\text {I.nndon FTF }}$ & & & $\begin{array}{r}0.163^{*} \\
(0.009) \\
\end{array}$ & -0.012 \\
\hline
\end{tabular}

\section{Notes:}

1. $A=\left[\begin{array}{ccc}a_{11} & 0 & 0 \\ 0 & a_{22} & 0 \\ 0 & 0 & a_{33}\end{array}\right]$

2. $\bar{\varepsilon}_{i}$ is the mean return shock.

3. * denotes $1 \%$ level.

4. Standard errors are given in parentheses.

5. London ETF Spot is a generated variable. 
Table 13: Diagonal BEKK for Hedging UK NBP Spot

\begin{tabular}{cccc}
\hline VAR(1) & $\boldsymbol{r}_{\text {NBPS }}$ & $\boldsymbol{r}_{H H F}$ & $\boldsymbol{r}_{F C G}$ \\
\hline$r_{N R P S}(-1)$ & 0.015 & 0.013 & -0.025 \\
& $(0.021)$ & $(0.021)$ & $(0.019)$ \\
$r_{H H F}(-1)$ & $0.111^{*}$ & $-0.095 *$ & -0.010 \\
& $(0.021)$ & $(0.022)$ & $(0.019)$ \\
$r_{F C f_{1}}(-1)$ & 0.007 & 0.035 & -0.013 \\
& $(0.024)$ & $(0.025)$ & $(0.022)$ \\
$C$ & -0.005 & -0.064 & -0.066 \\
& $(0.061)$ & $(0.063)$ & $(0.054)$ \\
\hline
\end{tabular}

\begin{tabular}{|c|c|c|c|}
\hline BEKK & $\boldsymbol{A}$ & & $\overline{\hat{\varepsilon}_{i}}$ \\
\hline$r_{N R P S}$ & $\begin{array}{l}0.295^{*} \\
(0.006)\end{array}$ & & -0.005 \\
\hline$r_{H H F}$ & $\begin{array}{l}0.211^{*} \\
(0.013)\end{array}$ & & -0.032 \\
\hline$r_{F C G}$ & & $\begin{array}{l}0.228^{*} \\
(0.011)\end{array}$ & -0.097 \\
\hline
\end{tabular}

Notes:

1. $A=\left[\begin{array}{ccc}a_{11} & 0 & 0 \\ 0 & a_{22} & 0 \\ 0 & 0 & a_{33}\end{array}\right]$

2. $\bar{\varepsilon}_{i}$ is the mean return shock.

3. * denotes $1 \%$ level.

4. Standard errors are given in parentheses. 
Table 14: Co-Volatility Spillovers for Hedging Henry Hub and UK NBP Spot

\begin{tabular}{|c|c|c|c|}
\hline & i & $j$ & $\begin{array}{c}\text { Mean Co-Volatility Spillovers } \\
\left(\partial Q_{i j t} / \partial \varepsilon_{i t-1}\right)\end{array}$ \\
\hline \multirow{4}{*}{$\begin{array}{l}\text { HHS } \\
\text { (USA) }\end{array}$} & $r_{H H S}$ & $r_{N R P F}$ & $0.364 \times 0.297 \times(-0.016)=-0.0017$ \\
\hline & $r_{N B P F}$ & $r_{H H S}$ & $0.364 \times 0.297 \times 0.037=0.0040$ \\
\hline & $r_{H H S}$ & $r_{\text {l.nndon FTF }}$ & $0.364 \times 0.163 \times(-0.012)=-0.0007$ \\
\hline & $r_{\text {I.nndon FTF }}$ & $r_{H H S}$ & $0.364 \times 0.163 \times 0.037=0.0022$ \\
\hline \multirow{4}{*}{$\begin{array}{l}\text { NBP } \\
\text { (UK) }\end{array}$} & $r_{N B P S}$ & $r_{H H F}$ & $0.295 \times 0.211 \times(-0.032)=-0.002 C$ \\
\hline & $r_{H H F}$ & $r_{N R P S}$ & $0.295 \times 0.211 \times(-0.005)=-0.0003$ \\
\hline & $r_{N R P S}$ & $r_{F C r}$ & $0.295 \times 0.228 \times(-0.097)=-0.0065$ \\
\hline & $r_{F C C_{t}}$ & $r_{N R P S}$ & $0.295 \times 0.228 \times(-0.005)=-0.0003$ \\
\hline
\end{tabular}

Notes:

1. Co-volatility spillovers are from market $i$ to $j$.

2. London ETF Spot is a generated variable. 
Table 15: Diagonal BEKK for Spot Prices

\begin{tabular}{ccc}
\hline VAR(1) & $\boldsymbol{r}_{H H S}$ & $\boldsymbol{r}_{N B P S}$ \\
\hline \multirow{2}{*}{$r_{H H S}(-1)$} & $0.097^{*}$ & -0.004 \\
& $(0.021)$ & $(0.017)$ \\
$r_{N R P S .}(-1)$ & 0.025 & 0.024 \\
& $(0.026$ & $(0.021)$ \\
$C$ & -0.058 & -0.012 \\
& $(0.076)$ & $(0.062)$ \\
\hline
\end{tabular}

\begin{tabular}{c|cc|c}
\hline BEKK & \multicolumn{1}{|c|}{$\boldsymbol{A}$} & $\overline{\widehat{\varepsilon}_{i}}$ \\
\hline$r_{H H S}$ & $\begin{array}{l}0.365^{*} \\
(0.012)\end{array}$ & 0.039 \\
$r_{N R P S}$ & & $\begin{array}{l}0.297^{*} \\
(0.007)\end{array}$ & -0.030 \\
\hline
\end{tabular}

Notes:

1. $A=\left\lceil\begin{array}{cc}a_{11} & 0 \\ 0 & a_{22}\end{array}\right]$

2. $\bar{\varepsilon}_{i}$ is the mean return shock.

3. * denotes $1 \%$ level.

4. Standard errors are given in parentheses. 
Table 16: Diagonal BEKK for Futures

\begin{tabular}{ccc}
\hline VAR(1) & $r_{H H F}$ & $r_{N R P F}$ \\
\hline$r_{H H F}(-1)$ & $-0.087^{*}$ & $0.112^{*}$ \\
& $(0.021)$ & $(0.020)$ \\
$r_{N R P F}(-1)$ & 0.016 & 0.020 \\
& $(0.021)$ & $(0.021)$ \\
$C$ & -0.066 & -0.005 \\
& $(0.063)$ & $(0.061)$ \\
\hline
\end{tabular}

\begin{tabular}{c|cc|c}
\hline BEKK & \multicolumn{1}{|c|}{$\boldsymbol{A}$} & $\overline{\bar{\varepsilon}_{\boldsymbol{i}}}$ \\
\hline$r_{H H F}$ & $\begin{array}{l}0.228^{*} \\
(0.014)\end{array}$ & & -0.020 \\
$r_{N R P F}$ & & $0.303^{*}$ & -0.005 \\
\hline
\end{tabular}

\section{Notes:}

1. $A=\left[\begin{array}{cc}a_{11} & 0 \\ 0 & a_{22}\end{array}\right]$

2. $\bar{\varepsilon}_{i}$ is the mean return shock.

3. * denotes $1 \%$ level.

4. Standard errors are given in parentheses. 
Table 17: Diagonal BEKK for ETF Spot

\begin{tabular}{ccc}
\hline VAR(1) & $r_{F C G}$ & $r_{\text {Landon FTF }}$ \\
\hline$r_{F C G}(-1)$ & -0.020 & $0.037^{*}$ \\
& $(0.022)$ & $(0.005)$ \\
$r_{\text {l.nndon FTF }}(-1)$ & 0.005 & -0.004 \\
$C$ & $(0.090)$ & $(0.021)$ \\
& -0.065 & -0.009 \\
& $(0.055)$ & $(0.013)$ \\
\hline
\end{tabular}

\begin{tabular}{c|cc|c}
\hline BEKK & \multicolumn{1}{|c|}{$\boldsymbol{A}$} & $\overline{\widehat{\varepsilon}_{\boldsymbol{i}}}$ \\
\hline$r_{F C C_{\mathrm{t}}}$ & $0.257^{*}$ & & -0.103 \\
$r_{\text {Inndon FTF }}$ & $(0.013)$ & $0.186^{*}$ & -0.012 \\
\hline
\end{tabular}

Notes:

1. $A=\left\lceil\begin{array}{cc}a_{11} & 0 \\ 0 & a_{22}\end{array}\right\rceil$

2. $\bar{\varepsilon}_{i}$ is the mean return shock.

3. * denotes $1 \%$ level.

4. Standard errors are given in parentheses.

5. London ETF Spot is a generated variable. 
Table 18: Co-volatility Spillovers for Spot, Futures and ETF Spot

\begin{tabular}{|c|c|c|c|}
\hline Market & i & $j$ & Mean Co-volatility Spillovers $\left(\partial Q_{i j t} / \partial \varepsilon_{i t-1}\right)$ \\
\hline \multirow{2}{*}{ Spot } & $r_{H H S}$ & $r_{N R P S}$ & $0.365 \times 0.297 \times(-0.030)=-0.0033$ \\
\hline & $r_{N R P S}$ & $r_{H H . S}$ & $0.365 \times 0.297 \times 0.039=0.0042$ \\
\hline \multirow{2}{*}{ Futures } & $r_{H H F}$ & $r_{N R P F}$ & $0.228 \times 0.303 \times(-0.005)=-0.0003$ \\
\hline & $r_{N R P F}$ & $r_{H H F}$ & $0.228 \times 0.303 \times(-0.020)=-0.0014$ \\
\hline \multirow{2}{*}{ ETF } & $r_{F C r_{1}}$ & $r_{\text {I.nndon FTF }}$ & $0.257 \times 0.186 \times(-0.012)=-0.0006$ \\
\hline & $r_{\text {I.nndon FTF }}$ & $r_{F C r_{t}}$ & $0.257 \times 0.186 \times(-0.103)=-0.004 \mathrm{C}$ \\
\hline
\end{tabular}

\section{Notes:}

1. Co-volatility spillovers are from market $i$ to $j$.

2. London ETF Spot is a generated variable. 